\title{
ANALISIS KEBERTERIMAAN SISTEM INFORMASI AKUNTANSI PERUSAHAAN MANUFAKTUR DI INDONESIA
}

\author{
CANTIKA SARI SIREGAR \\ IKA PERMATASARI \\ PUJIONO
}

\author{
Universitas Negeri Surabaya, Jl. Ketintang, Surabaya, Indonesia \\ cantikasiregar@unesa.ac.id, ikapermatasari@unesa.ac.id, pujiono@unesa.ac.id
}

\begin{abstract}
Accurate Accounting Software is the best financial and accounting application with the most brands used in Indonesia. With the presence of this Accounting Information System (AIS), the study aims to determine the behavioral intentions of companies in implementing the Accurate Accounting Software system with the UTAUT (Unified Theory of Acceptance and Use of Technology) model. This study uses a quantitative approach with a population of 14 manufacturing companies in Indonesia and a sample of 221 respondents. Confirmatory Factor Analysis using the SEM-PLS algorithm with PLS Warp software. Descriptive analysis results show that the majority of respondents have high levels of performance expectations, business expectations, social influence, facilitation conditions, and user behavior. In contrast, the level of the behavioral intention of most respondents is moderate. Spearman's correlation test results indicate that performance expectations, effort expectations, social influence, and facilitation conditions have a significant correlation $(p$-value $<0.01)$ on behavioral intentions. Likewise, facilitating conditions and behavioral intentions have a positive and significant correlation with user behavior ( $p$ value $<0.05)$.
\end{abstract}

Keywords: Accounting information system, UTAUT, SEM-PLS, accurate accounting software

Abstrak: Accurate Accounting Software merupakan aplikasi keuangan dan akuntansi terbaik dengan brand terbanyak digunakan di Indonesia. Dengan hadirnya Accurate Accounting Software sebagai Sistem Informasi Akuntansi (SIA), maka penelitian bertujuan untuk mengetahui niat perilaku pada perusahaan dalam implementasi sistem aplikasi Accurate Accounting Software dengan model UTAUT (Unified Theory of Acceptance and Use of Technology). Penelitian ini menggunakan pendekatan kuantitatif dengan populasi 14 perusahaan manufaktur di Indonesia dan sampel 221 responden. Analisis Faktor Konfirmatori menggunakan algoritma SEM-PLS dengan perangkat lunak PLS Warp. Hasil analisis deskriptif menunjukkan bahwa mayoritas responden memiliki tingkat harapan kinerja yang tinggi, harapan usaha, pengaruh sosial, kondisi fasilitasi, dan perilaku pengguna, sedangkan tingkat niat perilaku sebagian besar responden adalah sedang. Hasil uji korelasi Spearman menunjukkan bahwa ekspektasi kinerja, ekspektasi upaya, pengaruh sosial, dan kondisi fasilitasi memiliki korelasi yang signifikan ( $p$ value $<0,01$ ) pada niat perilaku. Demikian pula, kondisi memfasilitasi dan niat perilaku memiliki korelasi positif dan signifikan dengan perilaku pengguna ( $p$-value $<0,05$ ).

Kata kunci: Sistem informasi akuntansi, UTAUT, SEM-PLS, accurate accounting software 


\section{PENDAHULUAN}

Perkembangan teknologi yang sangat cepat memberikan pengaruh yang sangat signifikan pada sistem informasi akuntansi (SIA) dalam suatu perusahaan. Dengan adanya globalisasi, mengharuskan sebuah perusahaan mempunyai cara kerja yang cepat untuk memberikan pelayanan kepada customer dan pelaporan yang terupdate setiap saat, dampak yang dirasakan secara nyata dari keberadaan SIA adalah pemrosesan data yang mengalami perubahan dari sistem manual ke sistem komputer dan hadirnya aplikasi untuk akuntansi yang dapat mempermudah dalam membuat laporan keuangan (Nawaz \& Sheham, 2015).

SIA memungkinkan perusahaan untuk mengelola bisnisnya dengan manfaat potensial dari peningkatan alur proses, mengurangi inventaris, analisis data yang lebih baik, layanan pelanggan yang lebih baik, dan peningkatan margin keuntungan (Trigo, Belfo, \& Estébanez, 2016). Mogontha, Nangoi, \& Gerungai, (2017) lebih lanjut menegaskan bahwa banyak perusahaan tidak memiliki sumber daya yang cukup karena waktu implementasi yang panjang dan biaya tinggi yang terkait dengan SIA. Dalam sistem informasi akuntansi berbasis komputer, pemrosesan data dilakukan oleh komputer secara terintegrasi dengan satu kali pengerjaan saja (Geerts, Graham, Mauldin, McCarthy, \& Richardson, 2013). Prosesnya dapat dibagi tiga yaitu input, proses, dan output. Keuntungan yang dapat dirasakan perusahaan dengan adanya sistem akuntansi selain bisa menghasilkan laporan keuangan secara otomatis dan cepat, laporan yang dihasilkan akan lebih transparan dan memiliki tingkat akurasi yang lebih baik dibandingkan secara manual (Akay et al., 2016). Pada aplikasi SIA terdapat fasilitas sistem pengamanan password dan hak akses pengguna, namun tidak sedikit pengguna mengalami permasalahan dalam penerapannya, sehingga masih banyak perusahaan yang enggan menggunakan sistem informasi akuntansi berbasis komputer. Berdasarkan latar belakang diatas, penelitian ini ingin menganalisis penerimaan dan kesuksesan dari implementasi aplikasi accurate accounting software pada perusahaan manufaktur di Indonesia.

\section{Performance Expectancy}

Performance Expectancy (PE) merupakan tingkatan di mana seseorang mempercayai penggunaan sistem akan membantu untuk mendapatkan keuntungan kinerja dalam organisasi. Dalam konsep ini adalah kombinasi variabel yang diperoleh dari model penelitian sebelumnya tentang penerimaan dan penggunaan model teknologi (Venkatesh, Morris, Davis, \& Davis, 2003). Variabelnya adalah: perceived usefulness (F. D. Davis, 1989), extrinsic motivation (F. D. Davis, 1989), job fit (Sussman \& Siegal, 2003), relative advantage (Moore \& Benbasat, 1991) dan outcome expectations (Sussman \& Siegal, 2003). Berdasarkan bukti empiris, mereka dipisahkan menjadi performance expectancy dan personal expectancy (Compeau \& Higgins, 1995; A. Davis, 2017). Kegunaan dalam hal ini merupakan tingkatan di mana munculnya niat seseorang terhadap penggunaan sistem yang dapat meningkatkan kinerja dalam bekerja (Hartini \& Afnisari, 2013). Dari beberapa penjelasan yang disajikan di atas, dapat disimpulkan bahwa ada hubungan dari performance expectancy dengan behavior intention.

$\mathrm{H}_{1}$ Performance Expectancy berpengaruh positif terhadap Behavior Intention

\section{Effort Expectation}

Effort Expectation adalah tingkat kemudahan dalam penggunaan sistem yang akan dapat mengurangi upaya (usaha dan waktu) seseorang dalam melakukan pekerjaan mereka (Venkatesh et al., 2003). Variabelvariabel ini dirumuskan berdasarkan tiga konstruksi dalam model atau teori sebelumnya, 
yaitu Perceived Ease of Use dari model Technology Acceptance Model (TAM), Complexity, dan Ease of use (Venkatesh et al., 2003). Oh, Lehto, \& Park, (2009) mengidentifikasi bahwa kemudahan penggunaan mempengaruhi penggunaan teknologi informasi. Kemudahan penggunaan teknologi informasi akan menyebabkan niat perilaku pada seseorang bahwasanya sistem memiliki manfaat dan, oleh karena itu, menciptakan rasa nyaman ketika bekerja (Zhang, McAdams, Shankar, \& Darani, 2017). Beberapa indikator kemudahan penggunaan Teknologi Informasi (TI), yaitu: TI adalah hal yang mendasar untuk dipahami, TI melakukan dengan mudah apa yang diinginkan oleh penggunanya, keterampilan penggunanya akan meningkat dengan menggunakan $\mathrm{Tl}$, dan $\mathrm{TI}$ sangat mudah dioperasikan. Dari beberapa penjelasan yang diberikan di atas, pengguna teknologi informasi percaya bahwa teknologi informasi yang lebih fleksibel, mudah dimengerti, dan mudah dioperasikan akan menghasilkan minat dalam menggunakan teknologi informasi dan juga akan menggunakan teknologi informasi (Venkatesh et al., 2003). Sehingga dapat disimpulkan bahwa ada hubungan dari effort expectancy dengan behavior intention.

$\mathrm{H}_{2}$ Effort Expectation berpengaruh positif terhadap Behavior Intention

\section{Social Influence}

Social Influence didefinisikan sebagai sejauh mana seseorang merasakan orang lain mempengaruhinya menggunakan sistem baru (Hartini \& Afnisari, 2013). Social Influence merupakan faktor penentu perilaku dalam menggunakan teknologi informasi yang direpresentasikan sebagai subjective form dalam Theory of Reasoned Action (TRA), Theory of Acceptance Model (TAM), Theory of Planned Behavior (TPB), social factor (Venkatesh, Thong, \& Xu, 2016). Moore \& Benbasat, (1991) menyatakan bahwa pada lingkungan tertentu, penggunaan teknologi informasi akan meningkatkan status (image) seseorang dalam sistem sosial sehingga menimbulkan niat untuk menggunakan. Pengaruh sosial memiliki dampak pada perilaku individu melalui tiga mekanisme yaitu kepatuhan, internalisasi, dan identifikasi (Hansen, Saridakis, \& Benson, 2018; Hassanein \& Head, 2007; Venkatesh et al., 2016).

$\mathrm{H}_{3}$ Social Influence berpengaruh positif terhadap Behavior Intention

\section{Facilitating Condition}

Facilitating Condition didefinisikan sebagai sejauh mana seseorang percaya bahwa infrastruktur organisasi dan teknis tersedia untuk mendukung sistem. Dalam konsep ini ada kombinasi variabel yang diperoleh dari model penelitian sebelumnya tentang penerimaan dan penggunaan model teknologi. Variabelnya adalah: perceived control behaviour (Ajzen \& Fishbein, 2005), facilitating conditions (Thompson, Higgins, \& Howell, 1991), dan compatibility (Moore \& Benbasat, 1991). Venkatesh et al., (2016) menyatakan bahwa dukungan infrastuktur yang dimiliki oleh organisasi, membuat seseorang betah menggunakan sistem baru

$\mathrm{H}_{4}$ Facilitating Condition berpengaruh positif terhadap Use Behavior

\section{Behavior Intention}

Behaviour Intention didefinisikan sebagai sejauh mana seseorang telah merumuskan rencana untuk melakukan atau tidak melakukan rencana tersebut pada masa depan (Cabrera-Sánchez \& Villarejo-Ramos, 2020). Munculnya niat dalam menggunakan sistem baru mengarah pada perilaku untuk menggunakan sistem tersebut secara terusmenerus (Venkatesh et al., 2016).

$\mathrm{H}_{5}$ Behavior Intention berpengaruh positif terhadap Use Behaviour 


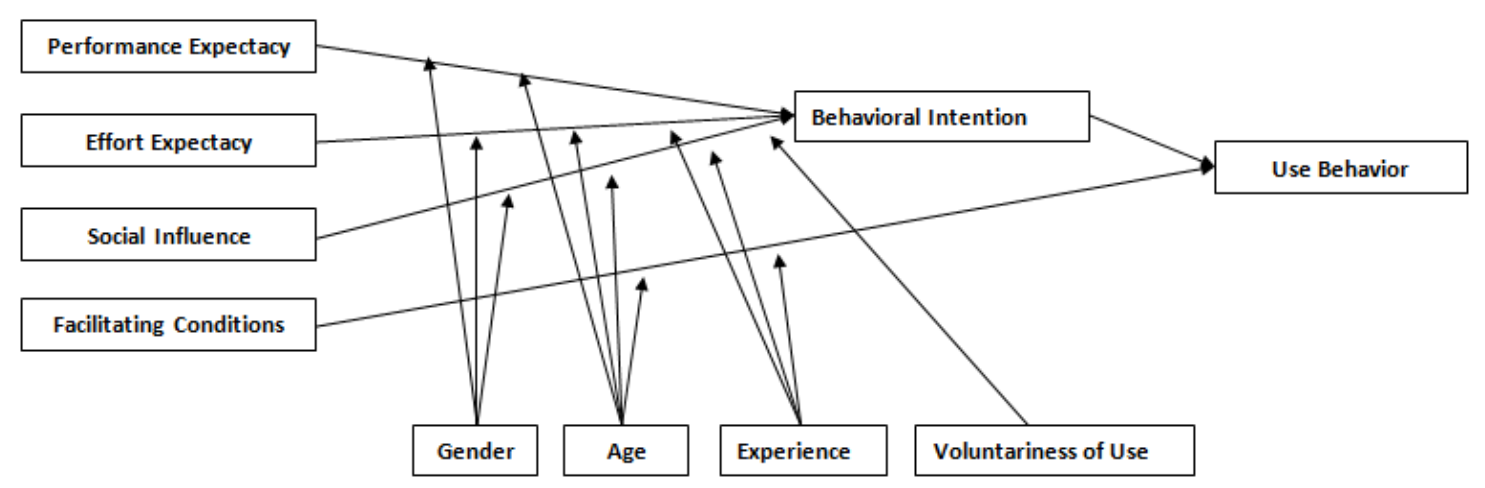

Gambar 1. Kerangka Penelitian UTAUT - Performance Expectancy, Effort Expectation, Social Influence, Facilitating Conditions, Behavior Intention (Venkatesh et al., 2016)

\section{METODE PENELITIAN}

Penelitian ini merupakan penelitian explanatory dengan pembuktian hipotesa yang dibangun melalui penggunaan beberapa variabel yang terdapat pada Unified Theory Of Acceptance And Use Of Technology (UTAUT), dengan purposive sampling menggunakan data primer sebagai sumber data, data dikumpulkan secara langsung untuk dilakukan analisa masalah yang diteliti melalui kuesioner. Populasi dari penelitian ini adalah pegawai perusahaan manufaktur dengan kriteria responden adalah pengguna aplikasi Accurate Accounting Software di perusahaan manufaktur yang telah menggunakan aplikasi lebih dari satu tahun dan responden memiliki usia 21 tahun ke atas.
Teknik analisis menggunakan Partial Least Square (PLS). Partial Least Square merupakan metode analitik yang kuat karena dapat diterapkan disemua skala data, tidak memerlukan banyak asumsi dan ukuran sampel tidak harus besar (Joseph F. Hair, Ringle, \& Sarstedt, 2011). Objek dalam penelitian ini adalah konstruk asli dalam model UTAUT, yang bertujuan untuk mengetahui faktor-faktor keberterimaan pengguna aplikasi Accurate Accounting Software pada perusahaan manufaktur di Indonesia. Indikator untuk mengukur setiap konstruk dalam UTAUT adalah turunan dari konstruk studi sebelumnya yang disajikan dalam Tabel 1 hingga Tabel 6:

Tabel 1 Konstruk performance expectations

\begin{tabular}{lll}
\hline \multicolumn{1}{c}{ Konstruk } & \multicolumn{1}{c}{ Definisi } & \multicolumn{1}{c}{ Indikator } \\
\hline $\begin{array}{l}\text { Perceived } \\
\text { Usefulness (F. D. } \\
\text { Davis, 1989) }\end{array}$ & $\begin{array}{l}\text { Sejauh mana seseorang percaya bahwa } \\
\text { menggunakan sistem tertentu akan } \\
\text { meningkatkan kinerja pekerjaannya. }\end{array}$ & $\begin{array}{l}\text { Menggunakan aplikasi Accurate } \\
\text { Accounting Software akan } \\
\text { meningkatkan efektivitas kegiatan } \\
\text { saya. }\end{array}$ \\
$\begin{array}{ll}\text { Extrinsic motivation } \\
\text { (F. D. Davis, 1989) }\end{array}$ & $\begin{array}{l}\text { Persepsi bahwa pengguna akan ingin } \\
\text { melakukan suatu kegiatan karena } \\
\text { dianggap berperan dalam mencapai hasil }\end{array}$ & - \\
& yang bernilai yang berbeda dari kegiatan &
\end{tabular}


itu sendiri, seperti peningkatan kinerja pekerjaan, pembayaran, atau promosi.

Job-fit (Thompson et al., 1991)

Relative Advantage (Moore \& Benbasat, 1991)

Performance

Expectations

(Sampson, Driscoll, Foulk, \& Carroll, 2010)
Bagaimana kapabilitas suatu sistem meningkatkan kinerja pekerjaan seseorang.

Sejauh mana menggunakan inovasi dianggap lebih baik daripada menggunakan sistem sebelumnya.

Ekspektasi hasil terkait dengan konsekuensi perilaku. Berdasarkan bukti empiris, mereka dipisahkan menjadi harapan kinerja dan harapan pribadi
Penggunaan aplikasi Accurate Accounting Software dapat mengurangi waktu yang dibutuhkan untuk bekerja.

Menggunakan aplikasi Accurate Accounting Software dapat meningkatkan produktivitas saya.

Dengan aplikasi Accurate Accounting Software akan meningkatkan kualitas output dan akan meningkatkan kuantitas hasil untuk jumlah usaha yang sama.

\section{Tabel 2 Konstruk effort expectations}

\begin{tabular}{lll}
\hline \multicolumn{1}{c}{ Konstruk } & \multicolumn{1}{c}{ Definisi } & \multicolumn{1}{c}{ Indikator } \\
\hline $\begin{array}{l}\text { Perceived Ease of } \\
\text { Use (Venkatesh et } \\
\text { al., 2016) }\end{array}$ & $\begin{array}{l}\text { Sejauh mana seseorang percaya bahwa } \\
\text { menggunakan sistem akan memudahkan } \\
\text { pekerjaan. }\end{array}$ & $\begin{array}{l}\text { Belajar mengoperasikan aplikasi } \\
\text { Accurate Accounting Software itu } \\
\text { mudah bagi saya. }\end{array}$ \\
& & $\begin{array}{l}\text { Mudah bagi saya untuk mempelajari } \\
\text { aplikasi Accurate Accounting Software. }\end{array}$ \\
$\begin{array}{l}\text { Complexity } \\
\text { (Compeau \& }\end{array}$ & Sejauh mana suatu sistem dianggap & Menggunakan aplikasi Accurate \\
Hengins, 1995; & relatif sulit untuk dipahami dan & Accounting Software melibatkan waktu \\
2016) & digunakan. & yang sangat sedikit untuk melakukan \\
Ease of Use (Moore & Sejauh mana menggunakan sistem & operasi mekanis (mis., Input pembelian \\
\& Benbasat, 1991; & Sebagai inovasi dianggap sulit untuk & Berinteraksi dalam mengoperasikan \\
Venkatesh et al., & digunakan. & sangati Accurate Accounting Software \\
2003) & & \\
\hline
\end{tabular}

Tabel 3 Konstruk Social Influence

\begin{tabular}{lll}
\hline \multicolumn{1}{c}{ Konstruk } & \multicolumn{1}{c}{ Definisi } & \multicolumn{1}{c}{ Indikator } \\
\hline Subjective Norm & Persepsi seseorang bahwa kebanyakan & Orang yang berpengaruh bagi saya \\
(Sussman \& Siegal, & orang yang penting baginya berpikir dia & berpikir bahwa saya harus \\
2003; Thompson et al., & harus atau tidak boleh melakukan & menggunakan aplikasi Accurate \\
1991; Venkatesh et al., & perilaku yang dimaksud. & Accounting Software. \\
2003) & &
\end{tabular}


Social Factors (Chih, Wang, Hsu, \& Huang, 2013)

Image (Compeau \& Higgins, 1995)
Internalisasi seseorang terhadap budaya dan perjanjian interpersonal yang telah dibuat dengan orang lain dalam situasi sosial tertentu.

Sejauh mana penggunaan suatu inovasi dirasakan dalam meningkatkan citra atau status seseorang pada sistem sosial seseorang.
Pihak manajemen telah mendukung dalam penggunaan aplikasi Accurate Accounting Software.

Secara umum, organisasi telah mendukung penggunaan aplikasi Accurate Accounting Software.

Orang-orang di organisasi saya yang menggunakan aplikasi Accurate Accounting Software memiliki prestise lebih dan memiliki profil tinggi daripada mereka yang tidak

\section{Tabel 4 Konstruk Facilitating Conditions}

\begin{tabular}{|c|c|c|}
\hline Konstruk & Definisi & Indikator \\
\hline $\begin{array}{l}\text { Perceived Behavioral } \\
\text { Control (Aghazadeh, } \\
\text { Sanaz; Kang, Yoon Ju; } \\
\text { Peytcheva, 2014; Ma, } \\
\text { Tse, Wang, \& Zhang, } \\
\text { 2019) }\end{array}$ & $\begin{array}{l}\text { Mencerminkan persepsi kendala internal } \\
\text { dan eksternal pada perilaku diri, kondisi } \\
\text { sumber daya, dan kondisi fasilitas } \\
\text { teknologi. }\end{array}$ & $\begin{array}{l}\text { Saya memiliki sumber daya yang } \\
\text { diperlukan untuk menggunakan aplikasi } \\
\text { Accurate Accounting Software. } \\
\text { Saya memiliki pengetahuan yang } \\
\text { diperlukan untuk menggunakan aplikasi } \\
\text { Accurate Accounting Software. }\end{array}$ \\
\hline $\begin{array}{l}\text { Facilitating Conditions } \\
\text { (Zhang et al., 2017) }\end{array}$ & $\begin{array}{l}\text { Faktor obyektif di lingkungan yang } \\
\text { membuat tindakan mudah dilakukan } \\
\text { termasuk penyediaan dukungan alat. }\end{array}$ & $\begin{array}{l}\text { Terdapat pelatihan/ pendampingan } \\
\text { dalam menggunakan aplikasi Accurate } \\
\text { Accounting Software. }\end{array}$ \\
\hline $\begin{array}{l}\text { Compatibility (Huang, } \\
\text { 2018; Zhang et al., } \\
\text { 2017) }\end{array}$ & $\begin{array}{l}\text { Sejauh mana inovasi dianggap konsisten } \\
\text { dengan nilai-nilai yang ada, kebutuhan, } \\
\text { dan pengalaman yang potensial. }\end{array}$ & $\begin{array}{l}\text { Saya pikir menggunakan aplikasi } \\
\text { Accurate Accounting Software cocok } \\
\text { dengan gaya kerja saya. }\end{array}$ \\
\hline
\end{tabular}

Tabel 5 Konstruk Behavioural Intention

\begin{tabular}{lll}
\hline \multicolumn{1}{c}{ Konstruk } & \multicolumn{1}{c}{ Definisi } & \multicolumn{1}{c}{ Indikator } \\
\hline Behavior Intention & Sejauh mana seseorang telah & Saya ingin menggunakan aplikasi \\
(Cabrera-Sánchez \& & merencanakan penentuan perilaku di & Accurate Accounting Software dalam \\
Villarejo-Ramos, 2020; & masa depan. & tiga bulan ke depan \\
Elwalda, Lü, \& Ali, & & Saya merasakan manfaat dari \\
$2016)$ & & menggunakan aplikasi Accurate \\
& & Accounting Software selama tiga bulan \\
& ke depan.
\end{tabular}


Satisfaction (llham, Niat positif untuk menggunakan atau 2018; Kheng, Mahamad, Ramayah, \&

Mosahab, 2010;

Sheikh, Yezheng, Islam, Hameed, \& Khan, 2019)
Saya akan menggunakan aplikasi Accurate Accounting Software untuk menyelesaikan pekerjaan dalam tiga bulan ke depan.

Saya akan terus menggunakan aplikasi Accurate Accounting Software jika fasilitasnya ditingkatkan.

Tabel 6 Konstruk Use Behaviour

\begin{tabular}{lll}
\hline \multicolumn{1}{c}{ Konstruk } & \multicolumn{1}{c}{ Definisi } & \multicolumn{1}{c}{ Indikator } \\
\hline Use Behaviour (De & Mencerminkan persepsi sistem dan & Saya sering menggunakan aplikasi \\
Spiegelaere, Van Gyes, & potensi penggunaan di masa depan. & Accurate Accounting Software \\
De Witte, Niesen, \& & & Saya lebih suka menggunakan aplikasi \\
Van Hootegem, 2014; & Accurate Accounting Software \\
Page, 2015; Sheikh et & dibandingkan dengan sistem manual. \\
al., 2019) & Sebagian besar kegiatan saya \\
& dilakukan menggunakan aplikasi \\
& Accurate Accounting Software. \\
& Setiap pembukuan saya selalu \\
& menggunakan aplikasi Accurate \\
& Accounting Software. \\
\hline
\end{tabular}

HASIL

Hasil survei dilakukan pada perusahaan manufaktur yang menggunakan aplikasi Accurate Accounting Software di Indonesia meliputi wilayah Jabodetabek, DIY Jogyakarta dan Jawa Timur, diperoleh 221 responden dari 250 kuesioner yang ditargetkan. Berdasarkan Tabel 7, usia dengan rentang 21 hingga 25 tahun dan gender wanita mendominasi pengguna aplikasi Accurate Accounting Software, hal ini selaras dengan survei yang dilakukan oleh Asosiasi Indonesia Internet Service Provider (APJII, 2017), yang menyatakan bahwasanya Generasi Z merupakan digital native yang telah terbiasa menggunakan aplikasi dan internet sehingga lebih mudah menerima sebuah sistem aplikasi baru, dan dalam hal ini gender wanita dipercaya lebih teliti dan cermat sehingga lebih cocok menggunakan aplikasi Accurate Accounting Software (Carter, Croft, Lukas, \& Sandstrom, 2019).

Tingkat validitas dapat diukur dengan membandingkan nilai rhitung dengan nilai $r$ tabel untuk degree of freedom (df) $=n-k$ dengan alpha 0,05 . Jika $r$ hitung lebih besar dari $r$ tabel dan nilai r positif, maka indikator dikatakan valid. Selain itu, validitas instrumen juga perlu diuji secara statistik, dengan melihat tingkat 
signifikansi untuk masing-masing instrumen, dalam hal ini, menggunakan skor Pearson Correlation sedangkan uji reliabilitas menggunakan Cronbach alpha, di mana instrumen dikatakan dapat diandalkan. atau dapat diandalkan jika memiliki koefisien reliabilitas 0,60 atau lebih. Uji validitas dan reliabilitas dilakukan dan diuji pada 221 responden secara acak. Hasil lengkap pengujian validitas dan reliabilitas disajikan pada Tabel 8.

Tabel 7 Demografi Responden

\begin{tabular}{rlccccccc}
\hline \multirow{2}{*}{ No Nama Perusahaan } & \multicolumn{4}{c}{ Usia } & \multicolumn{3}{c}{ Gender } & Total \\
\cline { 2 - 8 } & $\mathbf{2 1 - 2 5}$ & $\mathbf{2 6 - 3 0}$ & $\mathbf{3 1 - 3 5}$ & $\mathbf{> = 3 6}$ & $\mathbf{P}$ & $\mathbf{W}$ & \\
\hline 1 & PT. Megariamas Sentosa & 9 & 6 & 4 & - & 5 & 14 & 19 \\
2 & PT. Multi Anugerah Daya Garmindo & 3 & 10 & 7 & - & 6 & 14 & 20 \\
3 & PT Asian Collections Garments & 6 & 7 & 4 & 3 & 7 & 13 & 20 \\
4 & PT Grisina Garment Industries & 8 & 6 & 5 & 2 & 6 & 15 & 21 \\
5 & PT.Marga Cheetah Manufacturer & 4 & 5 & 2 & 2 & 4 & 9 & 13 \\
6 & CV. Kurnia Jaya Garment & 6 & 5 & 3 & - & 5 & 9 & 14 \\
7 & PT.Busana Prima Global & 4 & 4 & 2 & - & 6 & 4 & 10 \\
8 & PT Inti Cipta Nusantara & 6 & 5 & 4 & 1 & 5 & 11 & 16 \\
9 & PT. Olimpictindo Pratama & 4 & 3 & 3 & 5 & 4 & 11 & 15 \\
10 & Vaxa Group & 6 & 3 & 5 & - & 5 & 9 & 14 \\
11 & PT Farmer Cahaya Mandiri & 5 & 3 & 2 & 3 & 5 & 8 & 13 \\
12 & PT Pakar Ipal Indonesia & 6 & 3 & 4 & 2 & 7 & 8 & 15 \\
13 & PT. Kenko Sinar Ritelindo & 6 & 4 & 2 & - & 4 & 8 & 12 \\
14 & PT Indonesia Polyurethane Industry & 4 & 4 & 5 & 6 & 8 & 11 & 19 \\
\hline
\end{tabular}

Tabel 8 menunjukkan bahwa $r$ hitung lebih besar dari $r$ tabel $=0,361$ dengan alpha $=$ 0,05 atau $5 \%$ sehingga instrumen yang digunakan dalam penelitian ini dinyatakan valid untuk diujikan kepada responden. Pada Tabel 8 dapat dilihat bahwa hasil uji reliabilitas dengan nilai Cronbach Alpha dari masing-masing variabel yang digunakan dalam penelitian ini berada di atas 0,60 , yang berarti reliabel. Dengan demikian, dapat dikatakan bahwa semua variabel yang digunakan dalam penelitian ini dapat diandalkan.
Pengujian hipotesis yang diajukan dilakukan dengan melihat koefisien jalur, yang menunjukkan koefisien parameter dan nilai signifikansi statistik t. Signifikansi parameter yang diperkirakan dapat memberikan informasi tentang hubungan antara variabel-variabel penelitian. Batas untuk menolak dan menerima hipotesis yang diajukan adalah dengan menggunakan probabilitas 0,05 . Hasil analisis direpresentasikan oleh Gambar 2 dan Tabel 9. 
Tabel 8 Uji Validitas dan Reliabilitas

\begin{tabular}{|c|c|c|c|}
\hline Variabel & Dimensi & Coeff. Korelasi & Cronbach Alpha \\
\hline \multirow{4}{*}{ Performance Expectancy } & PE1 & 0.780 & \multirow{4}{*}{0.896} \\
\hline & PE2 & 0.890 & \\
\hline & PE3 & 0.804 & \\
\hline & PE4 & 0.830 & \\
\hline \multirow{4}{*}{ Effort Expectancy } & EE1 & 0.779 & \multirow{5}{*}{0.867} \\
\hline & EE2 & 0.795 & \\
\hline & EE3 & 0.784 & \\
\hline & EE4 & 0.791 & \\
\hline \multirow{4}{*}{ Social Influence } & Sl1 & 0.805 & \\
\hline & SI2 & 0.836 & \multirow{3}{*}{0.902} \\
\hline & SI3 & 0.825 & \\
\hline & SI4 & 0.872 & \\
\hline \multirow{4}{*}{ Facilitating Conditions } & FC1 & 0.814 & \multirow{4}{*}{0.902} \\
\hline & $\mathrm{FC} 2$ & 0.846 & \\
\hline & FC3 & 0.831 & \\
\hline & FC4 & 0.846 & \\
\hline \multirow{4}{*}{ Behavioral Intention } & Bl1 & 0.807 & \multirow{4}{*}{0.877} \\
\hline & $\mathrm{BI} 2$ & 0.831 & \\
\hline & $\mathrm{BI} 3$ & 0.760 & \\
\hline & $\mathrm{B} \mid 4$ & 0.802 & \\
\hline Age & kkp6 & 1.000 & \multirow{8}{*}{0.879} \\
\hline Gender & KS6 & 1.000 & \\
\hline Experience & KS5 & 1.000 & \\
\hline Voluntariness & V & 1.000 & \\
\hline \multirow{4}{*}{ Use Behavior } & KS1 & 0.806 & \\
\hline & KS2 & 0.838 & \\
\hline & KS3 & 0.733 & \\
\hline & KS4 & 0.835 & \\
\hline
\end{tabular}




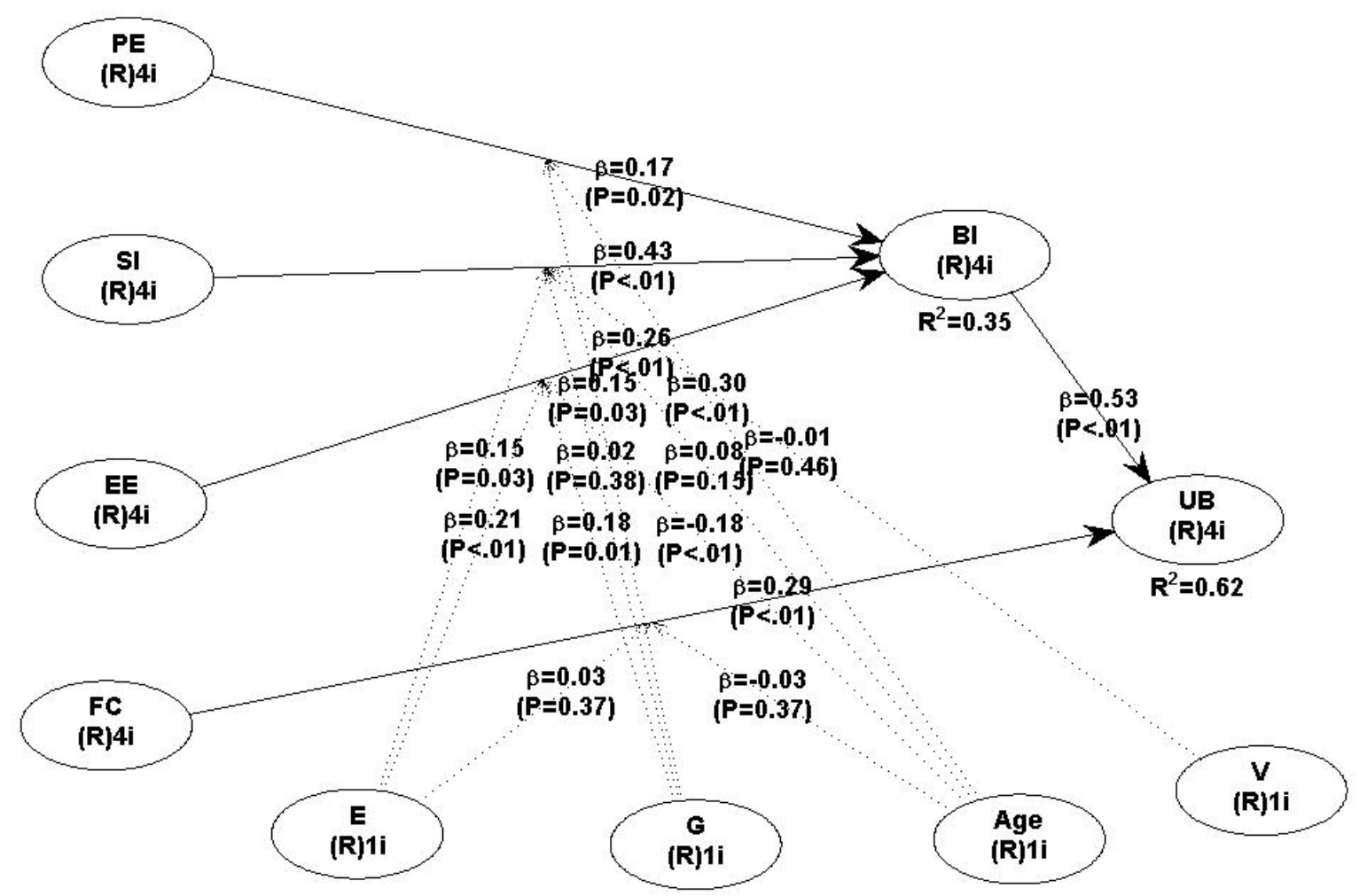

Gambar 2. Model Analysis using Warp PLS

Tabel 9 Hasil Uji Hipotesis

\begin{tabular}{ll}
\hline \multicolumn{1}{c}{ Variabel } & P-value \\
\hline Performance Expectancy --> Behavioral Intention & 0.019 \\
Effort Expectancy --> Behavioral Intention & 0.001 \\
Social Influence --> Behavioral Intention & 0.001 \\
Facilitating Conditions --> Use Behavior & 0.001 \\
Behavioral Intention --> Use Behavior & 0.001 \\
\hline
\end{tabular}

Hasil uji hipotesis pertama adalah hubungan antara variabel Kinerja Harapan dengan Behavioral Intention yang menunjukkan nilai-p 0,019<0,05. Berdasarkan hasil ini dapat disimpulkan bahwa Performance Expectancy memiliki efek positif pada Behaviour Intention ( $\mathrm{H}_{1}$ diterima). Dengan peningkatan Performance Expectancy yang dimiliki oleh seseorang dalam menggunakan aplikasi Accurate Accounting Software, itu akan berdampak pada Behavioral Intention. Penelitian ini sejalan dengan Abdullah Naheb (2017); Palau-Saumell, Forgas-Coll, Sánchez-García, \& Robres (2019); Sair \&
Danish (2018) yang menyatakan bahwa performance expectancy mempengaruhi behaviour intention. Dalam penelitian ini, aplikasi Accurate Accounting Software dapat mengakomodasi niat perilaku dalam menggunakan aplikasi sistem informasi akuntansi, dengan segala kelebihan yang dimiliki oleh Accurate Accounting Software, mulai dari modul pelaporan pajak yang terkini hingga layanan purna jual, .

Hasil hipotesis kedua adalah hubungan antara variabel Effort Expectancy dan Behavioral Intention yang menunjukkan nilai p- 
value $<0,001<0,05$. Berdasarkan hasil ini dapat disimpulkan bahwa Effort Expectancy memiliki efek positif pada Behavioral Intention $\left(\mathrm{H}_{2}\right.$ diterima). Dengan meningkat-nya Effort Expectancy, dapat meningkatkan Behavioral Intention. Menurut penelitian yang dilakukan oleh Ghalandari (2012); Venkatesh et al. (2016) yang menyatakan effort expectancy mempengaruhi behaviour intention. Dalam sistem organisasi, agar berjalan dengan efektif dan efisien membutuhkan sebuah sistem informasi teknologi. Pada dunia bisnis digital saat ini, penggunaan sistem informasi berbasis komputer sangat dibutuhkan demi belangsungnya proses bisnis di organisasi, dalam penelitian ini aplikasi Accurate Accounting Software sangat menunjang dalam proses sistem informasi akuntansi, dengan tampilan yang mudah dipahami, cara penggunaan yang yang praktis dan di dukung dengan teknologi dashboard smartphone membuat aplikasi ini makin banyak diminati oleh perusahaan manufaktur.

Hipotesis ketiga adalah bahwa hubungan antara variabel Social Influence dengan Behavioral Intention menunjukkan nilai $p$-value $0,001<0,05$. Berdasarkan hasil ini dapat disimpulkan bahwa Social Influence memiliki efek positif pada Behaviour Intention (diterima $\mathrm{H}_{3}$ ). Dengan meningkatkan Social Influence maka dapat meningkatkan Behaviour Intention. Ada banyak penelitian yang membahas pengaruh positif dari social influence terhadap behaviour intention, seperti penelitian yang dilakukan oleh Graf-Vlachy \& Buhtz (2017), yang membahas pengaruh social influence terhadap behaviour intention. Dalam penelitian ini, ratarata penerapan aplikasi Accurate Accounting Software oleh perusahaan di awali dengan pelatihan, agar para pegawai dapat melakukan pekerjaan dengan cepat, sehingga perusahaan dapat merasakan manfaat dengan sesegera mungkin, dan lingkungan pengguna dalam perusahaan saling berkompetisi untuk menjadi mahir dalam menggunakan aplikasi, kemudahan penggunaan aplikasi dapat mengarahkan pengaruh sosial untuk meningkatkan niat perilaku dalam menggunakan aplikasi yang akurat.

Hipotesis keempat adalah hubungan antara variabel facilitating conditions dan the use behaviour yang menunjukkan nilai p-value 0,001 $<0,05$. Berdasarkan hasil ini dapat disimpulkan bahwa facilitating conditions memiliki efek positif pada the use behaviour ( $\mathrm{H}_{4}$ diterima). Dengan meningkat-kan dukungan fasilitas yang dimilikioleh organisasi maka dapat meningkatkan perilaku pengguna sistem tersebut. Penelitian dilakukan oleh PalauSaumell et al. (2019); Venkatesh et al. (2016); Zhang et al. (2017) menyimpulkan bahwa facilitating conditions memiliki pengaruh positif pada perilaku pengguna. Dalam penelitian ini, fasilitas yang dimiliki Accurate Accounting Software sebagai sistem informasi akuntansi cukup memadai dalam menyelesaikan pekerjaan yang berkaitan dengan proses akuntansi, disamping kebutuhan spesifikasi aplikasi yang relatif rendah, aplikasi ini ringan dengan database yang terintegrasi dan fasilitas backup/restore sehingga tidak membutuhkan server yang terlalu besar.

Hasil hipotesis kelima adalah hubungan antara variabel behavioral intention dan use behavior, yang menunjukkan nilai $p$-value 0,001 $<0,05$. Berdasarkan hasil ini dapat disimpulkan bahwa behavioral intention memiliki efek positif pada use behavior (H5 diterima). Sehingga dengan meningkatkan behavioural intention, dapat meningkatkan use behavior. Ajzen \& Fishbein $(1980,2005)$ dalam penelitiannya menjelaskan bahwa niat perilaku memiliki efek positif pada perilaku pengguna, dalam penelitian ini penggunaan aplikasi Accurate Accounting Software yang diterapkan oleh perusahaan khususnya manufaktur penggunaan aplikasi tidak hanya sebatas penjualan dan pembelian, namun juga proses produksi, dan kegiatan ini dilakukan setiap hari, sehingga penggunaan aplikasi yang digunakan setiap hari, dan merasakan manfaat dari aplikasi tersebuat dapat meningkatkan sikap pengguna terhadap 
sistem aplikasi, sehingga pengguna dapat secara positif menerima implementasi aplikasi Accurate Accounting Software.

Selanjutnya, berdasarkan hasil bahwa variabel gender memoderasi variabel performance expectancy dengan behaviour intention dengan nilai $p 0,028<0,05$ dan variabel gender memoderasi variabel effort expectancy dengan behaviour intention dengan nilai $p 0,011$ $<0,05$, sebaliknya variabel gender tidak memoderasi variabel social influence dengan the use behaviour dengan nilai $p \quad 0,382>0,05$ sejalan dengan penelitian yang dilakukan oleh Hart, Stockdale, \& Stockdale (2009) bahwa performance expectancy dan effort expectancy sangat memengaruhi behaviour intention. Variabel usia memoderasi variabel performance expectancy dengan behaviour intention dengan $p$-value $0,001<0,05$ dan dan variabel umur memoderasi variabel ekspektasi usaha dengan intensi perilaku dengan nilai $p$-value 0,010 $<0,05$, sebaliknya variabel umur tidak memoderasi variabel pengaruh sosial dengan intensi perilaku dengan $p$-value $0,153>0,05$ dan variabel usia tidak memoderasi variabel effort expectancy dengan behaviour intention dengan $p$-value $0,366>0,05$. Variabel experience memoderasi variabel social influence dengan behaviour intention dengan $p$-value $0,030<0,05$ dan memoderasi variabel effort expectancy dengan behaviour intention dengan $p$-value $0,005<0,05$, disamping itu variabel experiences tidak memoderasi variabel facilitating conditions dengan the use behaviour dengan nilai $p$-value $0,372>0,05$. selanjutnya variabel volunteer tidak memoderasi variabel social influence dengan behaviour intention dengan nilai-p 0,459>0,05.

\section{PENUTUP}

Hasil penelitian ini menunjukkan bahwa UTAUT adalah model yang berguna untuk menjelaskan keberterimaan dan penggunaan aplikasi Accurate Accounting System di perusahaan manufaktur. Hasil analisis deskriptif menunjukkan bahwa mayoritas responden memiliki tingkat performance expectancy yang tinggi, effort expectancy, social influence, facilitating condition, dan behaviour intention, sedangkan tingkat the use behaviour sebagian besar responden adalah sedang. Hasil uji spearman correlation menunjukkan bahwa performance expectancy, effort expectancy, social influence, dan facilitating condition masing-masing memiliki korelasi positif dan signifikan ( $p$-value $<0,01$ ) pada behaviour intention. Demikian juga behaviour intention memiliki korelasi positif dan signifikan dengan the use behaviour ( $p$-value $<0,05$ ). Sementara facilitating condition tidak memiliki korelasi yang signifikan dengan the use behaviour.

Dampak dari penelitian ini dapat dirasakan langsung oleh para perusahaan dalam menerapkan sebuah sistem baru khususnya perusahaan manufaktur, dimana kompleksibilitas dalam proses produksi, dari hulu ke hilir dapat di atur menggunakan sistem informasi yang terintegrasi (Xerri, Brunetto, \& Shacklock 2009). Selain itu dengan fasilitas tambahan lain seperti pelaporan pajak yang dapat di modifkasi mengikuti perkembangan nya. Untuk ke depan nya, mungkin bisa ditambahkan modul modul lain untuk melengkapi fungsi dari aplikasi seperti Human Resource Information System (HRIS) yang meliputi penggajian, renumerasi hingga rekruitmen (Alshibly 2014). 


\section{REFERENCES:}

Abdullah Naheb, O. 2017. the Influence of Critical Factors on the Behavior Intention To Computerized Accounting Systems (Cas) in Cement Manufactures in Libya. The International Journal of Accounting and Business Society, 25(1), 86-108.

Aghazadeh, Sanaz; Kang, Yoon Ju; Peytcheva, M. 2014. How do Behavioral Indicators of Audit Committee Effectiveness Influence Audit Effort? (April 2014). Retrieved from http://isarhq.org/2014_downloads/papers/ISAR2014_Aghazadeh_Kang_Peytcheva.pdf

Ajzen, I., \& Fishbein, M. 1980. Understanding Attitudes and Predicting Social Behavior. the University of Michigan: Englewood Cliffs, N.J. : Prentice-Hall.

Ajzen, I., \& Fishbein, M. 2005. The Influence of Attitudes on Behavior. Journal of Social Psychology, 44(1), 115127.

Akay, E., Poputra, A., Kalalo, M., Marantika 2016. Analisis Aspek Keperilakuan Terhadap Penerapan Sistem Akuntansi Persediaan Pada Pt. Surya. Wenang Indah Manado. 688 Jurnal EMBA, 4(1), 688-697.

Alshibly, H. H. 2014. Evaluating E-HRM success: A Validation of the Information Systems Success Model. International Journal of Human Resource Studies, 4(3), 107.

APJII. 2017. Penetrasi \& Perilaku Pengguna Internet Indonesia. In teknopreneur (Vol. 2018). Retrieved from https://web.kominfo.go.id/sites/default/files/Laporan Survei APJII_2017_v1.3.pdf

Cabrera-Sánchez, J.-P., \& Villarejo-Ramos, Á. F. 2020. Acceptance and use of big data techniques in services companies. Journal of Retailing and Consumer Services, 52(July 2019), 101888.

Carter, A. J., Croft, A., Lukas, D., \& Sandstrom, G. M. 2019. Correction: Women's visibility in academic seminars: Women ask fewer questions than men (PLOS ONE (2019) 13: 9 (e0202743) DOI: 10.1371/journal.pone.0202743). PLOS ONE, 14(2), 212146.

Chih, W.-H., Wang, K.-Y., Hsu, L.-C., \& Huang, S.-C. 2013. Investigating Electronic Word-of-Mouth Effects on Online Discussion Forums: The Role of Perceived Positive Electronic Word-of-Mouth Review Credibility. Cyberpsychology, Behavior, and Social Networking, 16(9), 658-668.

Compeau, D. R., \& Higgins, C. A. 1995. Computer Self-Efficacy: Development of a Measure and Initial Test. MIS Quarterly, 19(2), 189.

Davis, A. 2017. Failures in adopting green technology under perfect pollution pricing and monopoly. International Review of Economics Education, 26(March), 9-13.

Davis, F. D. 1989. Perceived Usefulness, Perceived Ease of Use, and User Acceptance of Information Technology. MIS Quarterly, 13(3), 319.

De Spiegelaere, S., Van Gyes, G., De Witte, H., Niesen, W., \& Van Hootegem, G. 2014. On the relation of job insecurity, job autonomy, innovative work behaviour and the mediating effect of work engagement. Creativity and Innovation Management, 23(3), 318-330.

Elwalda, A., Lü, K., \& Ali, M. 2016. Perceived derived attributes of online customer reviews. Computers in Human Behavior, 56, 306-319.

Geerts, G. L., Graham, L. E., Mauldin, E. G., McCarthy, W. E., \& Richardson, V. J. 2013. Integrating information technology into accounting research and practice. Accounting Horizons, 27(4), 815-840.

Ghalandari, K. 2012. The Effect of Performance Expectancy, Effort Expectancy, Social Influence and Facilitating Conditions on Acceptance of E-Banking Services in Iran: the Moderating Role of Age and Gender. MiddleEast Journal of Scientific Research, 12(6), 801-807.

Graf-Vlachy, L., \& Buhtz, K. 2017. Social influence in technology adoption research: A literature review and research agenda. Proceedings of the 25th European Conference on Information Systems, ECIS 2017, 2017, 2331-2351.

Hansen, J. M., Saridakis, G., \& Benson, V. 2018. Risk, trust, and the interaction of perceived ease of use and behavioral control in predicting consumers' use of social media for transactions. Computers in Human Behavior, 80, 197-206.

Hart, K. C., Stockdale, R., \& Stockdale, R. 2009. Exploring the Gender Divide : Perceptions of IT Professionals in New Zealand. 
Hartini, S., \& Afnisari, K. 2013. Unified Theory of Acceptance and Use of Technology (UTAUT) Pada Penggunaan Aplikasi Akuntansi Terhadap Kinerja Karyawan. Pilar Nusa Mandiri, IX(2), 113-122.

Hassanein, K., \& Head, M. 2007. Manipulating perceived social presence through the web interface and its impact on attitude towards online shopping. International Journal of Human Computer Studies, 65(8), 689-708.

Huang, R. T. 2018. What motivates people to continuously post selfies? The moderating role of perceived relative advantage. Computers in Human Behavior, 80, 103-111.

Ilham, R. 2018. Improve Quality Of E-Loyalty In Online Food Delivery Services : A Case Of Indonesia. Journal of Theoretical and Applied Information Technology, 96(15), 4760-4769.

Joseph F. Hair, J., Ringle, C., \& Sarstedt, M. 2011. PLS-sem: Indeed a silver bullet. In The Journal of Marketing Theory and Practice (Vol. 19).

Kheng, L. L., Mahamad, O., Ramayah, T., \& Mosahab, R. 2010. The Impact of Service Quality on Customer Loyalty: A Study of Banks in Penang, Malaysia. International Journal of Marketing Studies, 2(2), 57-66.

Ma, J., Tse, Y. K., Wang, X., \& Zhang, M. 2019. Examining customer perception and behaviour through social media research - An empirical study of the United Airlines overbooking crisis. Transportation Research Part E: Logistics and Transportation Review, 127(April), 192-205.

Mogontha, W., Nangoi, G. B., \& Gerungai, N. 2017. ANALISIS PENGARUH ASPEK KEPERILAKUAN TERHADAP SISTEM AKUNTANSI. Jurnal Riset Akuntansi Going Concern, 3(1), 1177-1204.

Moore, G. C., \& Benbasat, I. 1991. Development of an Instrument to Measure the Perceptions of Adopting an Information Technology Innovation. Information Systems Research, 2(3), 192-222.

Nawaz, S. S., \& Sheham, A. M. 2015. Evaluating the Intention to use Accounting Information Systems by Small and Medium Sized Enterpreneurs. Research Journal of Finance and Accounting, 6(22), 38-48.

Oh, S., Lehto, X. Y., \& Park, J. 2009. Travelers' intent to use mobile technologies as a function of effort and performance expectancy. Journal of Hospitality and Leisure Marketing, 18(8), 765-781.

Page, D. 2015. Teachers' personal web use at work. Behaviour and Information Technology, 34(5), 443-453.

Palau-Saumell, R., Forgas-Coll, S., Sánchez-García, J., \& Robres, E. 2019. User Acceptance of Mobile Apps for Restaurants: An Expanded and Extended UTAUT-2. Sustainability, 11(4), 1210.

Sair, S. A., \& Danish, R. Q. 2018. Effect of performance expectancy and effort expectancy on the mobile commerce adoption intention through personal innovativeness among Pakistani consumers. Pakistan Journal of Commerce and Social Science, 12(2), 501-520.

Sampson, J. P., Driscoll, M. P., Foulk, D. F., \& Carroll, P. S. 2010. Successful Faculty Performance in Teaching, Research and Original Creative Work, and Service. (850), 1-17.

Sheikh, Z., Yezheng, L., Islam, T., Hameed, Z., \& Khan, I. U. 2019. Impact of social commerce constructs and social support on social commerce intentions. Information Technology and People, 32(1), 68-93.

Sussman, S. W., \& Siegal, W. S. 2003. Informational Influence in Organizations: An Integrated Approach to Knowledge Adoption. Information Systems Research, 14(1), 47-65.

Thompson, R. L., Higgins, C. A., \& Howell, J. M. 1991. Personal Computing: Toward a Conceptual Model of Utilization. MIS Quarterly, 15(1), 125.

Trigo, A., Belfo, F., \& Estébanez, R. P. 2016. Accounting Information Systems: Evolving towards a Business Process Oriented Accounting. Procedia Computer Science, 100, 987-994.

Venkatesh, Morris, Davis, \& Davis. 2003. User Acceptance of Information Technology: Toward a Unified View. MIS Quarterly, 27(3), 425.

Venkatesh, V., Thong, J. Y. L., \& Xu, X. 2016. Unified Theory of Acceptance and Use of Technology: A Synthesis and the Road Ahead. Journal of the Association for Information Systems, 17(5), 328-376.

Xerri, M., Brunetto, Y., \& Shacklock, K. 2009. [X] The innovative behaviour of employees within a small to medium sized enterprise : a social capital perspective. Proceedings, (December), $1-4$.

Zhang, G., McAdams, D. A., Shankar, V., \& Darani, M. M. 2017. Modeling the evolution of system technology performance when component and system technology performances interact: Commensalism and amensalism. Technological Forecasting and Social Change, 125(July), 116-124. 